University of Nebraska - Lincoln

DigitalCommons@University of Nebraska - Lincoln

M. Eugene Rudd Publications

Research Papers in Physics and Astronomy

1968

\title{
Optimum Spacing of Square and Circular Coil Pairs
}

\author{
M. Eugene Rudd \\ University of Nebraska - Lincoln, erudd@unl.edu \\ J. R. Craig \\ University of Nebraska - Lincoln
}

Follow this and additional works at: https://digitalcommons.unl.edu/physicsrudd

Part of the Physics Commons

Rudd, M. Eugene and Craig, J. R., "Optimum Spacing of Square and Circular Coil Pairs" (1968). M. Eugene Rudd Publications. 41.

https://digitalcommons.unl.edu/physicsrudd/41

This Article is brought to you for free and open access by the Research Papers in Physics and Astronomy at DigitalCommons@University of Nebraska - Lincoln. It has been accepted for inclusion in M. Eugene Rudd Publications by an authorized administrator of DigitalCommons@University of Nebraska - Lincoln. 


\title{
Optimum Spacing of Square and Circular Coil Pairs*
}

\author{
M. E. Rudd and J. R. Craig \\ Behlen Laboratory of Physics, University of Nebraska, \\ Lincoln, Nebraska 68508
}

(Received 18 March 1968, and in final form, 13 May 1968)

TN a previous note Crownfield ${ }^{1}$ pointed out that the 1 magnetic field along the axis of a coil pair is within a prescribed uniformity over a substantially longer region than that given by the Helmholtz spacing if a somewhat larger spacing is used. In the note, values of coil spacing and length of uniform field region are given for a few 
FIG. 1. Magnetic field along the axis of a circular coil pair for various coil spacings. Field is expressed as a fraction of central field. The distance along the axis and the coil spacing are measured in units of the radius of the coils. The same set of curves can be used for square coil pairs with small error provided the distance and spacing are measured in units of the Helmholtz spacing, which for square coils is 0.5445 times the length of a side.

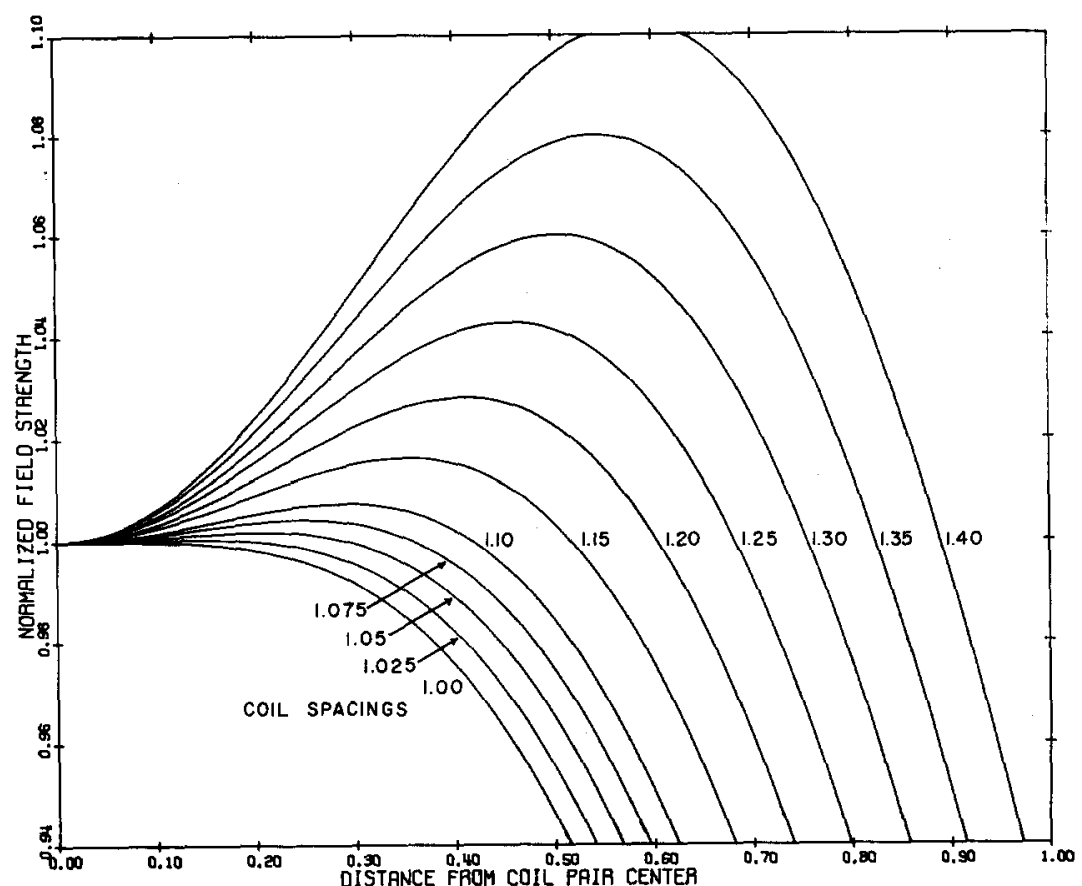

desired uniformities, but only for a particular "thick" coil pair, i.e., one with cross-sectional dimensions comparable to the spacing. Many coil pairs, such as those used to annul the earth's field over the region occupied by some apparatus, have cross-sectional dimensions which are small compared to the spacing. This note presents calculations for such "thin" coils, both circular and square. Square coils have some advantages, as recently pointed out by Firester, ${ }^{2}$ who calculated field deviations both off axis and on axis for square coil pairs but only for coils at the Helmholtz spacing.

The Helmholtz spacing is the coil separation for which the second derivative of the field vanishes at the center. For circular coils this spacing is equal to half the diameter of the coils; for square coils it is ${ }^{2}$ equal to 0.5445 times the length of a side. Our computer computations reveal that the field variation along the axis of both square and circular coil pairs is very similar provided both the position and coil spacing are measured in units of the Helmholtz spacing. With this scaling, data for circular coils can be used for square coils with at most a $6 \%$ error over the entire region of our calculations.

Figure 1 shows the field, normalized to the central field, along the axis of a coil pair for various spacings. The extended range of uniformity is evident. We define the field variation for the optimum spacing to be half the difference between the central and maximum field and express it as a fraction of the average of these two fields. The length of uniform field is taken as the distance between points where the field falls from its maximum back to the central value. Figure 2(a) shows the calculated field varia-
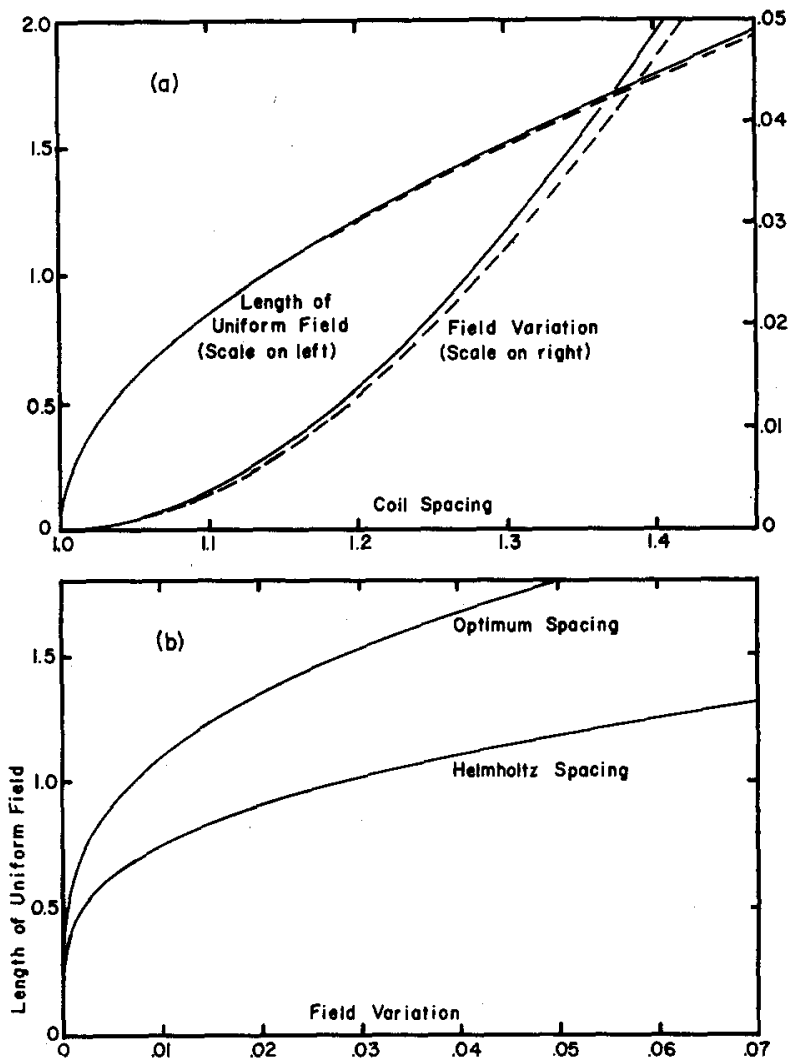

Fig. 2. (a) Field variation and length of uniform field for circular (solid lines) and square (dashed lines) coils. The length of uniform field is measured in units of the Helmholtz spacing. (b) Comparison of length of field of a designated uniformity for circular coils at the Helmholtz spacing and at the optimum spacing. The length is in units of the radius. For square coils the curves are similar, but about $1 \%$ higher, provided the length of uniform field is measured in units of the Helmholtz spacing. 
tions and length of uniform field as functions of coil spacing. At first the field variation rises slowly with increasing coil spacing while the length of the uniform field region increases relatively rapidly. As the spacing is increased, a point of diminishing returns is reached, but even at a spacing $20 \%$ greater than the Helmholtz spacing, the field is within $\pm 1.5 \%$ of the average value over the entire length of the axis from one coil plane to the other.

In Fig. 2(b) we compare coils at the optimum spacing with those at the Helmholtz spacing. For the latter spacing we measure the length of uniform field to the point where the field falls to twice the designated variation below the central (maximum) field. A 40 to $50 \%$ increases in length of the uniform field is obtained by changing from the Helmholtz to the optimum spacing. Thus the new spacing is distinctly superior, unless field uniformity far off-axis is equally important as on-axis field uniformity.

* Supported by the National Science Foundation.

1 Frederic R. Crownfield, Jr., Rev. Sci. Instr. 35, 240 (1964).

2 Arthur H. Firester, Rev. Sci. Instr. 37, 1264 (1966). 